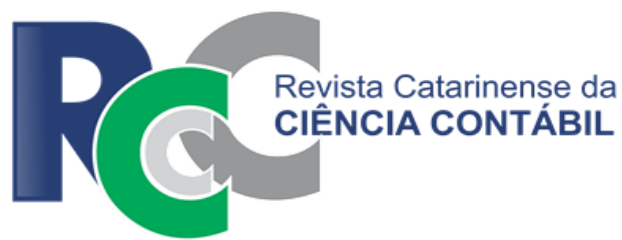

ISSN 2237-7662, Florianópolis, SC, v. 19, 1-18, e2906, 2020

\title{
PAYOUT INCREMENTAL E O MODELO DE TRÊS FATORES DE FAMA E FRENCH
}

\section{PAYOUT INCREMENTAL AND FAMA \& FRENCH THREE FACTOR MODEL}

\author{
KLIVER LAMARTHINE ALVES CONFESSOR \\ Universidade Federal do Vale do São Francisco. Endereço: Rua Antônio \\ Figueira Sampaio, 134 | Nossa Sra. De Graças | 56000-000 | Salgueiro, \\ Pernambuco/PE $\mid$ Brasil. \\ (D)https://orcid.org/0000-0002-6972-634X \\ adm.kliver@gmail.com
}

\section{JOSÉTE FLORENCIO DOS SANTOS}

Universidade Federal de Pernambuco. Endereço: Av. Professor Moraes Rego, 1235. Centro de Ciências Sociais Aplicadas | Cidade Universitária | 50670-901 | Recife, Pernambuco/PE | Brasil.

(D)https://orcid.org/0000-0002-5366-2548

jfs@ufpe.br

\section{RESUMO}

Este artigo buscou investigar se o modelo adaptado de Fama e French com a inclusão do fator Payout (F\&F com Payout) permitiria melhor compreensão dos retornos das carteiras de companhias listadas na Brasil, Bolsa, Balcão entre o período de 2004 e 2018 do que o modelo de três fatores de Fama e French. O prêmio pelo fator Payout obtido pela diferença dos retornos entre as companhias que pagaram e aquelas que não pagaram Payout Incremental. Dessa forma, o modelo de quatro fatores é definido pela adição deste fator aos fatores prêmio pelo risco de mercado (RM-RF), prêmio pelo fator tamanho da companhia (SMB), definido pelo valor de mercado do patrimônio líquido, e o prêmio pelo fator Book-to-market (HML), que é um índice definido pela relação valor contábil e valor de mercado do patrimônio líquido. Esse modelo de quatro fatores teve seu poder explicativo testado pelo retorno de doze carteiras criadas a partir da ortogonalização de seus fatores de risco. Os resultados sugerem que o modelo de quatro fatores foi mais eficiente do que o modelo de três fatores em explicar o retorno de oito das carteiras formuladas, com destaque para uma capacidade explicativa de mais de $70 \%$ para as carteiras de menor valor (small) que não pagam dividendos e que pagam dividendos incrementais. Portanto assume um papel relevante para as decisões de investimentos em carteiras de ações que possuem distribuição de dividendos extremas. Além disso, o fator Payout foi significativo em nove das doze carteiras. Nas carteiras em que não houve pagamento de dividendos, seu impacto foi negativo, implicando dizer que quanto maior o retorno destas carteiras, menor é a probabilidade de existir um prêmio pelo fator Payout. Por sua vez, para as carteiras que pagaram dividendos mínimos e incrementais, existe relação direta com o retorno das carteias. Isto posto, esta pesquisa corrobora com as teorias da relevância dos dividendos de Lintner (1956) e Gordon (1959), na medida em que o modelo desenvolvido é relevante para os estudos de avaliação de portfólios.

Palavra-chave: Avaliação de portfólio. Formação de carteiras. Modelo de três fatores de Fama e French. Payout incremental. Dividendos. 


\begin{abstract}
This article sought to investigate whether the model adapted from Fama and French with the inclusion of the Payout factor ( $F \& F$ with Payout) would allow a better understanding of the returns of the portfolios of companies listed in Brazil, Bolsa, Balcão between 2004 and 2018 than the model of three factors from Fama and French. The Payout factor Award is obtained by calculating the difference in return between the companies that paid and those that did not pay Incremental Payout. Thus, this four-factor model is defined by the addition of this factor to the factors Award for market risk (RM-RF), Award for the size factor of the company (MbS), defined by the market value of equity, and the Premium by the Book-to-market factor ( HML), which is an index defined by the accounting value and market value ratio of equity. This 4-Factor model had its explanatory power tested by the return of 12 portfolios created from the orthogonalization of their risk factors and it was more efficient than the three-factor model in explaining the return of eight of the portfolios formulated, with emphasis on an explanatory capacity of more than $70 \%$ for the lower value (small) portfolios that do not pay dividends and pay incremental dividends, therefore assuming a relevant role for the investment decisions in portfolios that have extreme dividend distribution. In addition, the results show that the Payout factor was significant in nine of the twelve portfolios. In portfolios where there was no dividend payment, their impact was negative, implying that the higher the return of these portfolios, the lower the probability of a premium for the Payout factor. In turn, for the portfolios that paid minimum and incremental dividends, there is a direct relationship with the return of the cards. Thus, this study corroborates the theories concerning the relevance of dividends by Lintner (1956) and Gordon (1959).
\end{abstract}

Keywords: Portfolio valuation. Portfolio formation. Model of three factors of Fame and French. Incremental Payout. Dividends.

\title{
1 INTRODUÇÃO
}

A remuneração por meio de dividendo é um dos retornos mais almejados pelos quais os investidores confiam seus recursos na aquisição de parcelas do capital social de entidades, segundo Veiga, Imbrosio e Ferreira (2008), e por isso, ao investirem nas companhias, os acionistas anseiam que elas obtenham lucros e que, parte desse lucro, em formato de dividendos, seja direcionada para remunerá-los. Convém destacar que a remuneração por dividendos é isenta de imposto de renda desde 1996, o que a torna ainda mais atrativa aos investidores. Ademais, Almeida, Pereira e Tavares (2016) citam que a crescente procura por investimentos e pelo desenvolvimento do mercado de capitais é personificada na política de dividendos.

O pagamento de dividendos é regulamentado pela legislação societária brasileira, por meio da Lei $n^{\circ}$ 6.406/76, a qual apresenta, dentre as obrigatoriedades das companhias brasileiras de capital aberto, a distribuição dos seus lucros aos acionistas. A política de dividendo contempla decisões que procuram responder perguntas relacionadas à destinação dos lucros da companhia e possui íntima relação com as políticas de investimento e financiamento, por exemplo, ao indicar se a companhia reinvestirá o capital ou se distribuirá dividendos aos acionistas. Ao final de um exercício social, os gestores decidem qual será o percentual de retenção dos lucros e de remuneração dos acionistas e quando isso deverá acontecer.

Considerando a perspectiva dos investidores, percebe-se que a relevância da política dos dividendos reside no fato de que eles analisam os valores dos dividendos distribuídos pelas companhias como um dos critérios para decidir em qual delas irão investir. Na literatura de finanças, encontram-se diversos estudos que abordam a política de dividendos e sua capacidade 
de adicionar valor à companhia, com destaque para duas abordagens: a relevância dos dividendos (Lintner, 1956; Gordon, 1959) e a irrelevância dos dividendos (Miller \& Modigliani, 1961). Por outro lado, pesquisas científicas em finanças estão voltadas para entender os fatores que explicam o retorno das ações e, nesse sentido, formulam modelos de precificação com vistas a descobrir quais fatores-chave explicam com maior precisão o retorno dos ativos.

Para o estudo de dividendos das companhias de capital aberto no mercado brasileiro, observa-se a obrigatoriedade de que as políticas de dividendos estejam de acordo com as Leis no 6.404/1976 e no 9.249/1995. A primeira, denominada Lei das Sociedades por Ações, estabelece, entre outros assuntos, o pagamento mínimo de dividendos e sua periodicidade. Entre os artigos 201 e 205, verifica-se a obrigatoriedade de informar, no estatuto social, um percentual mínimo do Lucro Líquido Ajustado (LLA) que será destinado ao pagamento dos dividendos e, caso o estatuto não apresente essa informação, o dividendo obrigatório não poderá ser inferior a $50 \%$ do LLA.

Diante do contexto de distribuição de dividendos, Lintner (1956) e Gordon (1959) defendem a existência de uma relação entre o valor pago na forma de dividendos e o valor das ações, portanto é importante observar a política de distribuição de dividendos no mercado acionário brasileiro, investigando se é possível que o fator "pagamento de dividendos" se configure como um fator que explique o retorno das ações considerando-se a variação do Payout em relação ao mínimo exigido nos estatutos sociais.

Diante disso, o objetivo deste trabalho é investigar se o modelo adaptado de Fama e French com a inclusão do fator Payout (F\&F com Payout) permitiria melhor compreensão dos retornos das carteiras de companhias listadas na B3 do que o modelo de três fatores de Fama e French. Para alcançar esse objetivo, o poder explicativo do modelo de quatro fatores com Payout foi comparado com o modelo de três fatores de Fama e French e o efeito que cada fator de risco exerce sobre o retorno das carteiras formuladas. O estudo será realizado com empresas listadas na Brasil, Bolsa, Balcão para o período de 2004 a 2018.

Assim, vislumbra-se a oportunidade de incluir o Payout como um novo fator que pudesse melhor representar um ajuste ao modelo de três fatores de Fama e French. Adicionalmente, espera-se trazer uma importante contribuição para a expansão da literatura de finanças, especialmente no tocante à formação de carteiras de investimento; modelos de avaliação de ativo e principalmente gerar reflexões sobre a teoria da relevância dos dividendos na medida em que este estudo oferece resultados empíricos e discussões teóricas sobre a temática. Ante o exposto convém destacar que pesquisas anteriores, como as de Neves e Leal (2003), Malaga e Securato (2004), Joode (2011), Santos, Famá e Mussa (2012), Xiao, Faff, Gharghri e Lee (2013) e Azevedo (2014), incluíram os mais diversos fatores, porém reforçam que ainda existe espaço para novos fatores.

\section{REFERENCIAL TEÓRICO}

\subsection{Teoria da relevância dos dividendos}

A teoria da relevância dos dividendos defende que o aumento destes contribui para maximizar o valor da companhia. Nesse sentido, Gordon (1959) explica que altos pagamentos de dividendos reduzem o custo de capital de terceiros e, consequentemente, aumentam o valor das ações. Portanto os investidores que são avessos ao risco, ao se encontrarem em um ambiente de incerteza, preferem receber dividendos o quanto antes.

Essa teoria defende que os dividendos representam ganhos certos no presente e que a valorização da ação é um evento incerto no futuro. Posto isso pagar dividendos corrobora para reduzir a incerteza, o que, por sua vez, implica no aumento dos preços das ações da companhia. Assim identifica-se uma relação direta entre a política de dividendos e o valor de mercado da companhia (Gordon, 1963). 
Ainda conforme a relevância dos dividendos, Lintner (1956) concluiu que os gestores são relutantes em reduzir níveis de pagamento de dividendos e que só aumentam o pagamento destes quando estão convictos de que as companhias têm fluxo de caixa suficiente para mantê-lo, uma vez que os investidores interpretam mudanças inesperadas nos níveis de dividendos como uma mudança negativa da expectativa dos administradores em relação aos resultados futuros da companhia. Portanto reduzir os níveis de dividendos implicaria em desvalorizar as ações da companhia. Estudos posteriores (Baker, Farrelly \& Delman, 1985; Baker \& Powell, 1999), nos quais foram realizadas entrevistas com gestores a respeito do aumento dos dividendos, chegaram aos mesmos resultados que Lintner (1956).

Santana (2006) comenta que os dividendos afetam o valor da companhia porque alterações no montante de dividendos distribuídos aos acionistas revelam as expectativas dos administradores em relação às perspectivas futuras da companhia. Assim observa-se que não seria a preferência dos acionistas que levaria aos acréscimos nos preços das ações, e sim a expectativa de ganhos futuros a partir da retenção de lucros.

\subsection{Considerações legais dos dividendos no Brasil}

Nesta seção apresentam-se os aspectos relacionados ao tratamento legal dos dividendos e dos juros sobre capital próprio dentro do contexto do mercado acionário brasileiro, conforme a Comissão de Valores Mobiliários e as Leis $n^{\circ}$ 6.404/1976 e n ${ }^{\circ}$ 9.249/1995. O entendimento do tratamento legal dos dividendos dentro do contexto brasileiro permite compreender com mais afinco o conceito de Payout Incremental.

A Lei $n^{\circ}$ 6.404/176, conhecida como Lei das S/A, versa de forma geral sobre as obrigatoriedades quanto às decisões de pagamento de dividendos, as quais são tomadas em uma Assembleia Geral Ordinária (AGO) ou, para assuntos não mencionados no artigo 132 da Lei no 6.404/1976, uma Assembleia Geral Extraordinária (AGE).

A AGO deverá ser realizada até o quarto mês após o encerramento do exercício, e dentre seus objetivos está a deliberação sobre as demonstrações financeiras; a decisão sobre a distribuição do lucro líquido e o pagamento de dividendos. Em seguida, a companhia deverá informar à Bolsa de Valores a intenção do pagamento de dividendos.

A Lei das S/A, em seus artigos 201 a 205, rege sobre a normalização quanto aos dividendos. O artigo 201 apresenta que os dividendos podem ser originados do lucro líquido do exercício, dos lucros acumulados, das reservas de lucros e da conta de reserva do capital para o caso das ações preferenciais.

O artigo 202 contempla a instrução do dividendo mínimo obrigatório, cujo fundamento é a proteção do acionista minoritário em detrimento das arbitrariedades da administração ou dos acionistas majoritários. O dividendo mínimo obrigatório é definido como um percentual do lucro descrito no estatuto social da companhia. Ainda conforme o artigo 202, quando o estatuto social não informar o percentual de dividendo mínimo obrigatório, a companhia fica obrigada a distribuir pelo menos $50 \%$ do lucro líquido ajustado (LLA) do exercício como dividendo mínimo obrigatório.

Resumindo, quando o estatuto for omisso e a companhia convocar assembleia-geral para introduzir uma norma sobre a matéria, o dividendo obrigatório não poderá ser inferior a $25 \%$ do lucro líquido ajustado, salvo se o direito de retirada dos acionistas for garantido. Assim, quando a Lei $\mathrm{n}^{\mathrm{o}}$ 6.404/1976 entrou em vigor, as companhias existentes ficaram num dilema: manter o estatuto social omisso e se enquadrar no percentual de $50 \%$ como dividendo obrigatório; ou definir um percentual inferior a $25 \%$, mas ensejar direito de retirada aos acionistas descontentes. A maioria das empresas optou por um percentual de $25 \%$ do LLA, conforme consta em Galvão, Santos e Araújo (2018) e em Leite, Bogoni e Hein (2019), por exemplo.

Isto posto, a história nos mostra que companhias que surgiram após 1976 podem definir um dividendo obrigatório inferior a $25 \%$ do LLA. Contudo muitas acabaram estipulando o percentual de $25 \%$. Assim esse percentual acabou se transformando em padrão entre as 
companhias brasileiras, passando a ser reconhecido como o referencial do dividendo mínimo obrigatório (Leite, Bogoni \& Hein, 2019).

Uma observação importante na Lei das S/A é que as companhias estarão dispensadas de pagar o dividendo obrigatório quando os administradores comunicarem à AGO que, naquele exercício, pagar dividendos é incompatível com a situação financeira da companhia. Neste caso, portanto, não haverá distribuição dos lucros e estes deverão ser registrados como reserva especial, caso não sejam absorvidos por prejuízos em exercícios futuros, e deverão ser pagos como dividendos assim que a situação financeira da companhia permitir, conforme $\S 4^{\circ}$ do artigo 202.

No Brasil, os dividendos são isentos de tributação na pessoa física e jurídica. Assim quaisquer valores pagos como forma de remunerar acionistas deverão ser recebidos integralmente por eles. Em 1996, com a Lei ${ }^{\circ}$ 9.249/1995, foi criado um mecanismo de pagamento de dividendo: os Juros Sobre o Capital Próprio (JSCP), que tem caráter facultativo e permite que as companhias remunerem também seus acionistas por meio dele.

O pagamento de dividendos sob a forma de JSCP é classificado tributariamente como despesa dedutível da base de cálculo do imposto de renda, ou seja, constitui um benefício fiscal à companhia pagadora uma vez que pode ser deduzido da base de cálculo do Imposto de Renda e da Contribuição Social Sobre o Lucro Líquido (CSLL) para a companhia pagadora. Dessa forma, Decourt e Procianoy (2012) mencionam que os JSCP são utilizados pela maioria das companhias, dado o benefício fiscal. No entanto, para os investidores, os dividendos são isentos de imposto, enquanto os JSCP são tributáveis como receita financeira. A Tabela 1 ilustra as diferenças entre JSCP e os Dividendos.

Tabela 1

Diferença entre Juros Sobre Capital Próprio e Dividendos

\begin{tabular}{l|l}
\hline Juros Sobre Capital Próprio & Dividendos \\
\hline $\begin{array}{l}\text { Distribuição optativa vinculada à existência desta } \\
\text { condição no estatuto da companhia e à existência de } \\
\text { fluxos de caixa. }\end{array}$ & $\begin{array}{l}\text { Distribuição obrigatória vinculada à existência de } \\
\text { lucros e conforme declarado no estatuto das } \\
\text { companhias. }\end{array}$ \\
\hline Base de cálculo: patrimônio líquido. & Base de cálculo: lucro líquido ajustado. \\
\hline $\begin{array}{l}\text { Percentual de remuneração: limitado à variação da } \\
\text { Taxa de Juros de Longo Prazo (TJLP). }\end{array}$ & Percentual de distribuição: definido em estatuto. \\
\hline $\begin{array}{l}\text { Incidência de impostos para o acionista: é tributado na } \\
\text { fonte em 15\% sobre o valor distribuído. }\end{array}$ & $\begin{array}{l}\text { Incidência de impostos para o acionista: o valor } \\
\text { recebido não é tributado. }\end{array}$ \\
\hline $\begin{array}{l}\text { Situação fiscal para a companhia: os JSCP } \\
\text { distribuídos são considerados despesas financeiras e } \\
\text { reduzem a base de cálculo do IRPJ e da CSLL. }\end{array}$ & $\begin{array}{l}\text { Situação fiscal para a companhia: os dividendos } \\
\text { distribuídos não podem reduzir a base de cálculo do } \\
\text { IRPJ e da CSLL devidos pela companhia. }\end{array}$ \\
\hline Fonte: Adaptado de Lagioia, Maciel e Libonati (2008).
\end{tabular}

Diante do exposto, verifica-se que, de acordo com a Lei $\mathrm{n}^{\circ} 6.404 / 1976$, as companhias devem distribuir um dividendo obrigatório, ou seja, a distribuição de proventos conforme estabelecida no estatuto e definido nesta pesquisa por Payout mínimo.

Para calcular o Payout distribuído pelas companhias e poder identificá-lo como Payout mínimo, Payout incremental ou Payout reduzido, é preciso evidenciar o Payout pago a partir da razão do total de dividendos distribuídos (dividendos e JSCP) pelo LLA, como segue na Equação 1:

$$
\text { Payout Distribuído }=\frac{J S C P_{\text {Líquido }}+\text { Dividendos }_{\text {Pagos }}}{L L A} \quad \text { Equação } 1
$$

Sendo:

Payout distribuído: Proventos efetivamente pagos aos acionistas;

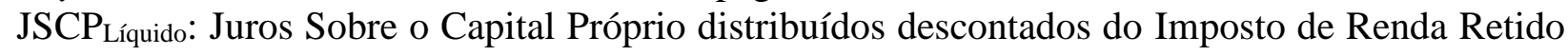
na Fonte; 
Dividendospagos: Dividendos pagos aos acionistas;

LLA: Lucro Líquido Ajustado.

Portanto, assim como Galvão, Santos e Araújo (2018), esta pesquisa utiliza o Payout mínimo obrigatório como referência para a classificação do Payout como mínimo, incremental ou reduzido, em função do que é determinado no estatuto social das companhias. Para os três níveis de Payout evidenciados nesta pesquisa, o Payout mínimo equivale ao percentual de pagamento de dividendos estabelecido no estatuto; o Payout incremental compreende o percentual de dividendos pago acima do estabelecido no estatuto social; e o Payout reduzido ocorre quando os dividendos distribuídos estiverem abaixo do nível informado no estatuto social.

\subsection{O Modelo de Fama e French e algumas de suas adaptações}

Diante da necessidade de entender melhor os retornos dos ativos e realizar avaliações de risco mais precisas, muitos estudos são direcionados para modelos de precificação de ativos. Os modelos Capital Asset Pricing Model (CAPM), Arbitrage Pricing Theory (APT) e o de três fatores de Fama e French (1993) são os mais conhecidos. O modelo CAPM pressupõe que a taxa de retorno de todos os ativos de risco é função do Beta $(\beta)$ de mercado, sendo este o único fator de medição do risco, conforme Lintner (1956).

O modelo APT, desenvolvido por Ross (1976), diferencia-se do CAPM ao entender que existe mais de um fator de risco que exerce influência sistemática sobre os ativos. De acordo com o autor, a associação entre o retorno esperado e as várias sensibilidades aos fatores Beta $(\beta)$ deve apresentar uma relação linear. Portanto verifica-se que, nos modelos de avaliação de ação, o prêmio de risco dos ativos é variável central na explicação dos retornos desses ativos (Vieira, Maia, Klotzle \& Figueiredo, 2017). Ademais, o uso do modelo APT é interessante pela possibilidade de incluir variáveis dentre os fatores macroeconômicos que relacionam a previsibilidade do retorno das ações.

O modelo de Fama e French (1993) é utilizado para explicar os retornos de ações e se apresenta como uma alternativa ao CAPM, pois, ao invés de utilizar um único fator (o retorno em excesso do mercado, que é o retorno das ações menos a taxa livre de risco), utiliza mais dois fatores de risco, como os fatores tamanho e valor. Além do fator excesso de retorno de mercado $\left(R_{m}-R_{f}\right)$, eles utilizaram os fatores SMB referentes ao tamanho (VM), que diz respeito ao valor de mercado da companhia. O modelo sugere que o investidor exija um retorno maior de ações de menor valor de mercado do que as ações de alto valor de mercado.

O terceiro fator de risco considerado pelo modelo de Fama e French (1993), denominado por Book-to-market, refere-se à razão entre valor patrimonial (VC) e valor de mercado (VM). Para esses autores, o investidor exige retorno maior de uma ação de alto valor do que de uma ação de baixo valor.

$\mathrm{O}$ modelo de três fatores de Fama e French está baseado na premissa de que o retorno esperado de uma carteira superior à taxa livre de risco $\left(\mathrm{R}_{\mathrm{t}}-\mathrm{R}_{\mathrm{f}}\right)$ é explicado pela sensibilidade de seu retorno por três fatores, sendo eles: (1) o excesso de retorno de uma carteira ampla do mercado $\left(\mathrm{R}_{\mathrm{m}}-\mathrm{R}_{\mathrm{f}}\right)$; (2) a diferença entre o retorno de uma carteira de pequenas companhias e o retorno de uma carteira de grandes companhias - Small Minus Big (SMB); (3) a diferença entre o retorno de uma carteira de ações de alto valor e o retorno de uma carteira de ações de baixo valor - High Minus Low (HML).

O fator tamanho também possui relação com a rentabilidade. Quando as companhias são agrupadas por esse fator, percebe-se que as pequenas companhias tendem a ter rentabilidade sobre o ativo menor do que as grandes. Posto isso os autores concluem que o efeito tamanho tem relação negativa com a rentabilidade média.

$\mathrm{O}$ fator valor relaciona-se aos fundamentos econômicos das companhias. Aquelas com altos índices VC/VM apresentam maiores probabilidades de ter baixos retornos sobre os ativos e, quando a companhia detiver baixos índices, espera-se que tenha elevados retornos sobre os 
ativos (Fama \& French, 1993), sendo estes, portanto, elementos úteis no processo de decisão de investimento em ações.

O primeiro passo do modelo de Fama e French é estimar o prêmio para cada um dos fatores de risco e, em seguida, analisar a relação desses fatores sobre o retorno das ações. Posto isso, é importante observar que o prêmio pelo risco é obtido pela diferença entre retorno esperado de um ativo num determinado tempo $(\mathrm{t})$ e o retorno do ativo livre de risco. O prêmio pelo tamanho é calculado pela diferença entre a carteira formada pelas companhias pequenas menos as formadas pelas companhias grandes (SMB). Por fim, o prêmio pelo fator valor é o resultado da diferença entre as companhias de alto e baixo valor (HML).

Dentre os principais resultados do estudo de Fama e French (1993), destaca-se o seguinte:

a) Foram encontrados prêmios positivos para todos os fatores de risco: mercado, tamanho e valor;

b) A maior parte das regressões das carteiras do modelo apresentou intercepto estatisticamente igual a zero, validando o modelo utilizado e indicando que os três fatores seriam proxies para os fatores de risco relevantes para os investidores;

c) Todos os fatores de risco se mostraram significativos e pareceram se complementar na explicação das variações dos retornos das carteiras.

Diante disso, Mussa, Rogers e Securato (2009) comentam que o modelo dos três fatores é válido para ser usado nas diversas decisões financeiras e é superior ao CAPM na explicação dos retornos das ações. Como consequência dos estudos de Fama e French (1993), muitos autores passaram a testar empiricamente a validade do modelo dos três fatores diante do modelo CAPM e a investigar o comportamento do retorno das ações a partir da inclusão de outros fatores de risco nos mais diversos mercados.

Neves e Leal (2003) investigaram se os fatores relacionados pelo modelo Fama e French (1993) têm alguma relação com o crescimento do PIB e outras variáveis macroeconômicas. Os resultados indicam que os fatores HML e SMB se mantiveram estatisticamente significativos: o HML apresentou relação inversa com o crescimento do PIB, e o SMB, relação direta, tal como foi identificado na Austrália, no Canadá e na Alemanha.

Por sua vez, Malaga e Securato (2004) investigaram se as variações dos retornos das ações no período 1995 a 2003 poderiam ser explicadas pelo modelo de três fatores. Adotaram a mesma metodologia aplicada por Fama e French (1993), definindo os retornos mensais dos prêmios dos fatores de risco e dos retornos das ações e carteiras. Testaram a significância do modelo e de cada um dos fatores observando-se o coeficiente de determinação, $R^{2}$ e a estatística $t$ de Student. Os resultados indicaram que o modelo de três fatores é superior ao CAPM na explicação dos retornos das ações da amostra utilizada e que os três fatores eram significantes.

Numa perspectiva de obter maiores explicações sobre quais fatores melhor explicam o retorno das ações diante da incapacidade do modelo de três fatores em explicar a variação crosssection do retorno das carteiras, Carhart (1997) adicionou o fator momento ao modelo de três Fatores de Fama e French (1993) e concluiu que o novo modelo reduziu substancialmente o erropadrão em relação ao modelo original.

Joode (2011) analisou o impacto da variável inovação ao modelo de Fama e French de três fatores na predição do retorno das ações, a partir da construção de dez carteiras com base na contagem de patentes, e concluiu que a inovação pode explicar o retorno das ações e a relevância do fator tamanho diminui diante da presença do fator inovação no modelo.

Santos, Famá e Mussa (2012) investigaram se o modelo de três fatores de Fama e French, com a inclusão da variável "momento", poderia explicar as variações dos retornos das ações brasileiras listadas na B3, no período de 1995 a 2006, e, para este fim, usaram a mesma metodologia adotada por Fama e French (1993). O modelo foi testado por meio do coeficiente de determinação e os resultados indicam que o modelo de quatro fatores é válido para o mercado acionário brasileiro e superior ao modelo de três fatores de Fama e French (1993) na explicação 
das variações dos retornos das ações da amostra, de forma que o fator momento impacta positivamente no retorno das ações.

Para testar o modelo de três fatores de Fama e French (1993) e verificar o impacto da inclusão do um quarto fator, a sustentabilidade, Xiao, Faff, Gharghri e Lee (2013) realizaram um estudo. A pesquisa contou com uma amostra inicial de 300 mil ativos e dados mensais no período entre 1999 e 2007 . Os resultados demostraram que os fatores tamanho e valor possuíam forte poder de explicação dos retornos das ações e não foram encontradas evidências de que o prêmio pelo fator sustentabilidade exercia impacto significativo nos retornos das ações dos países analisados.

O modelo de três fatores de Fama e French, com a inclusão do fator sustentabilidade, foi aplicado no Brasil por Azevedo (2014). O autor investigou se esse modelo permite melhor compreensão a respeito do retorno das ações no mercado acionário brasileiro entre os anos de 2006 e 2013. Os resultados demonstram que o prêmio pelo fator sustentabilidade empresarial é significante no modelo e possibilita o aumento do seu coeficiente de determinação. Além disso, o fator geralmente traz impacto negativo no retorno esperado das ações.

Ante o exposto, esta pesquisa realizou uma adaptação ao modelo de Fama e French com vistas a incluir o fator Payout, na expectativa de testar se esse novo modelo se sobrepõe ao modelo original de três fatores no sentido de explicar o retorno das carteiras de ações. Essa proposição está fundamentada na teoria da relevância dos dividendos, a qual sugere que o pagamento de dividendos contribui para adicionar valor às ações, conforme Lintner, (1962), Gordon (1963), Loss e Sarlo Neto (2006), Martins e Fama (2012) e de Melo e Fonseca (2015).

\section{ASPECTOS METODOLÓGICOS}

A partir das classificações da distribuição de dividendos como mínimo obrigatório, reduzido, incremental e o não pagamento de dividendos, pelo pressuposto do que é informado no estatuto social das companhias, esta pesquisa sugere um novo modelo de avaliação do retorno das ações a partir da inclusão do fator Payout ao modelo de três fatores de Fama e French, e investiga como este impacta nas explicações das variações dos ativos no mercado brasileiro.

A população deste estudo é formada por companhias listadas na Bolsa de Valores de São Paulo: Brasil, Bolsa e Balcão (B3). As companhias selecionadas compõem uma amostra não probabilística. Essa escolha se deu por oferecer certas vantagens, tais como conveniência, velocidade e baixo custo.

As informações necessárias para a aplicação do modelo de três fatores com a inclusão da variável Payout incremental, ou seja, o VM, a relação VC pelo $\mathrm{VM}$, o retorno das ações $\left(\mathrm{R}_{\mathrm{i}}\right)$ e o fator Payout, foram obtidas nos endereços eletrônicos das companhias, na seção de relação com investidores, bem como no endereço eletrônico da Comissão de Valores Mobiliários (CVM), B3, nas ata das AGO e na base de dados Economatica ${ }^{\circledR}$ para o período de 2004 a 2018 . A opção pelo ano 2004 se justifica pelo fato de ser a data mais antiga disponibilizada pela CVM nas atas de AGO e que seria possível obter informações suficientes para a construção das carteiras pela metodologia de Fama e French (1993).

Os critérios para a seleção da amostra foram:

a) Apresentar VM e/ou VC entre janeiro de 2004 e dezembro de 2018;

b) Apresentar valor do patrimônio líquido positivo. Fama e French (1993) excluem da amostra as companhias que apresentam patrimônio líquido negativo;

c) Não ter declarado outro tipo de distribuição como desdobramento de ações, dividendos em ações, fusões entre a declaração de dividendos prévios e a declaração de dividendos correntes;

d) Não ter apresentado mudanças anormais na variação de dividendos;

e) Não estar classificada entre as companhias do setor financeiro, dado o seu maior grau de alavancagem em comparação com as companhias dos demais setores, exercendo, portanto, influência sobre o índice B/M. Ademais, o endividamento de companhias do 
setor financeiro não possui o mesmo significado do endividamento de companhias não financeiras (Santos, Famá \& Mussa, 2012);

f) Apresentar cotações mensais consecutivas por 12 meses, a fim de viabilizar o cálculo do retorno das ações.

Este estudo segue a metodologia de Fama e French (1993) de formação das carteiras e cálculos dos fatores, prêmio pelo mercado, HML e SMB para formar e calcular o fator Payout. Diverge apenas quanto ao critério a manutenção da classificação medium (intermediaria) dos fatores HML e SMB utilizado para formar as carteiras, uma vez que, caso fosse contemplado, resultaria na formação de carteiras sem nenhum ativo.

Portanto foram criadas doze carteiras a partir da ortogonalização das carteiras criadas pela proxy VC, pela razão valor patrimonial e valor de mercado VC/VM e pela classificação do nível do pagamento de dividendos das companhias, conforme os seguintes procedimentos:

1. As ações foram ordenadas e divididas em dois grupos de acordo com o a mediana do VM, definidas como Big e Small.

2. Nova reordenação. As ações foram ordenadas e divididas em dois grupos, de acordo com o a mediana do índice VC/VM, definidas como High e Low.

3. Utilizando como referência o nível de pagamento de dividendos das companhias, a amostra foi dividida em três níveis: aquelas que não pagaram dividendos (Payout $\mathrm{n}_{\mathrm{t}}$ ), as companhias que pagaram Payout mínimo ou reduzido (Payout $\mathrm{mr}_{\mathrm{t}}$ ) e as que pagaram Payout incremental (Payout $\mathrm{i}_{\mathrm{t}}$ ), denominadas de "N", "MR" e "I", respectivamente.

Esses procedimentos foram repetidos anualmente, portanto as modelos de carteira foram balanceadas anualmente, com base em dezembro, e isso permitiu que as companhias mudassem de carteira de acordo com as análises dos seus índices.

As carteiras contemplaram as ações comuns entre os dois grupos de tamanho (Small e High) e os dois grupos de valor (Low e High), e os três grupos que indicam o perfil de pagamento de dividendos Payout $\mathrm{n}_{\mathrm{t}}$, Payout $\mathrm{i}_{\mathrm{t}}$, e Payout $\mathrm{mr}_{\mathrm{t}}$. A Tabela 2 ilustra a característica de cada modelo de carteira.

Tabela 2

Características das doze carteiras formadas para o cálculo dos fatores HML, SMB e Payout incremental

\begin{tabular}{l|l|l|l}
\hline Carteira & Tamanho & Valor & Payout \\
\hline S/L/N & Small & Low & $\left(\right.$ Payout $\left.n_{t}\right)$ \\
\hline S/H/N & Small & High & $\left(\right.$ Payout $\left.n_{t}\right)$ \\
\hline S/L/I & Small & Low & $\left(\right.$ Payout $\left.i_{t}\right)$, \\
\hline S/H/I & Small & High & $\left(\right.$ Payout $\left.i_{t}\right)$, \\
\hline S/L/MR & Small & Low & Payout mr \\
\hline S/H/MR & Small & High & Payout mr \\
\hline B/L/N & Big & Low & $\left(\right.$ Payout $\left.n_{t}\right)$ \\
\hline B/H/N & Big & High & $\left(\right.$ Payout $\left.n_{t}\right)$ \\
\hline B/L/I & Big & Low & $\left(\right.$ Payout $\left.i_{t}\right)$, \\
\hline B/H/I & Big & High & $\left(\right.$ Payout $\left.i_{t}\right)$, \\
\hline B/L/MR & Big & Low & Payout mr \\
\hline B/H/MR & Big & High & Payout mr \\
\hline Nota $\mathrm{ma} \mathrm{prig}$
\end{tabular}

Nota. Na primeira coluna está designada a nomenclatura de cada carteira formada nesta pesquisa. Na segunda coluna estão as denominações para carteiras de menor valor patrimonial (tamanho) e, na terceira coluna, as denominações para as carteiras com característica de baixo valor e de alto valor de mercado. Na última coluna estão listadas as classificações das companhias conforme a política de dividendos.

Fonte: Elaboração própria.

Após o cálculo dos quatro fatores (prêmio do mercado, tamanho, valor e Payout incremental), foram realizadas regressões pelo do método dos mínimos quadrados ordinários para obter os coeficientes das carteiras e medir o grau de ajuste e poder explicativo do modelo de 
três fatores de Fama e French com Payout incremental. A expressão pode ser visualizada na Equação 2:

$$
\mathrm{Rci}, \mathrm{t}-\mathrm{Rlrt}=\alpha+\beta(\mathrm{Rmt}-\mathrm{Rlrt})+\beta \text { SMBt }+\beta \mathrm{HMLt}+\beta \text { Payout } \mathrm{I}+\mathrm{ei,t} \quad \text { Equação } 2
$$

Sendo:

$\mathrm{Rci}, \mathrm{t}=$ retorno da carteira i no tempo $\mathrm{t}$;

$\mathrm{Rmt}=$ retorno da carteira de mercado no mês t;

Rlrt $=$ retorno do ativo livre de risco no mês t;

SMBt= Small Minus Big ou prêmio pelo fator tamanho no mês t, ou seja, a diferença entre a média de retorno das ações de empresas de menor porte e a média de retorno das ações de empresas de grande porte;

HMLt: High Minus Low ou prêmio pelo fator, ou seja, a diferença entre a média de retorno das ações com alto índice de valor contábil sobre valor de mercado e a média de retorno das ações com baixo índice valor contábil sobre valor de mercado;

Payout I: Payout incremental é o fator utilizado para identifica o montante de dividendos distribuídos, por empresa e acima do estabelecido no estatuto social;

ei, $\mathrm{t}=$ Resíduo do modelo referente à carteira i no tempo $\mathrm{t}$.

A variável dependente, denominada de prêmio de mercado da carteira, é calculada a partir do retorno anual da carteira em relação ao ativo livre de risco. Para a formação das variáveis independentes: (1) prêmio pelo fator de mercado: equivale ao retorno da carteira subtraindo o prêmio obtido pelos ativos livres de risco; (2) fator tamanho (SMB): referente ao prêmio obtido pela diferença de retorno entre companhias caracterizadas como Small ou Big; (3) fator valor ou razão (HML): equivale ao prêmio obtido pelas ações caracterizadas como High, Medium ou Low, ou seja, considera o excesso de retorno médio entre a carteira de alto índice BE/ME e baixo índice BE/ME; e (4) fator Payout é calculado a partir da diferença entre a média dos retornos anuais da carteira do grupo Payout mínimo. Ou seja, companhias que pagaram exatamente o valor dos dividendos declarados nas Atas de AGO, com a média da carteira das companhias classificadas pelo Payout incremental e a média do retorno das companhias que pagaram Payout reduzido. A Tabela 3 resume os procedimentos de cálculo para cada fator mencionado.

Tabela 3

Procedimentos para o cálculo dos fatores utilizados no modelo F\&F com Payout

\begin{tabular}{|c|c|}
\hline Fator & Definições \\
\hline Prêmio de mercado $=\left\lfloor\sum_{i=1}^{n} \frac{V M_{i, t}}{V_{p, t}}\left(R_{i, t}\right)\right\rfloor-R_{t}$ & $\begin{array}{l}\mathrm{VP}_{\mathrm{i}, \mathrm{t}}: \text { Valor patrimonial da ação } i \text { no mês } t ; \\
\mathrm{VM}_{\mathrm{i}, \mathrm{t}}: \text { Valor de mercado da ação } i \text { no mês } t ; \\
\mathrm{R}_{\mathrm{i}, \mathrm{t}}: \text { Retorno da ação } i \text { no mês } t \\
\mathrm{Rf}_{\mathrm{t}}: \text { Retorno do ativo livre de risco no mês } t \text {. }\end{array}$ \\
\hline Fator tamanho: $\mathrm{SMB}_{\mathrm{t}}=\overline{\mathrm{R}_{\mathrm{S}, \mathrm{t}}}-\overline{\mathrm{R}_{\mathrm{B}, \mathrm{t}}}$ & $\begin{array}{l}\mathrm{SMB}_{\mathrm{t}}: \text { Retorno pelo fator de risco tamanho no ano } t ; \\
\overline{\mathrm{R}_{\mathrm{S}, \mathrm{t}}}: \text { Retorno médio das três carteiras } S \text { no ano } t ; \\
\overline{\mathrm{R}_{\mathrm{B}, \mathrm{t}}}: \text { Retorno médio das quatro ou quartas carteiras } B \text { no } \\
\text { ano } t \text {. }\end{array}$ \\
\hline Fator valor ou razão $\mathrm{HML}_{\mathrm{t}}=\overline{\mathrm{R}_{\mathrm{H}, \mathrm{t}}}-\overline{\mathrm{R}_{\mathrm{L}, \mathrm{t}}}$ & $\begin{array}{l}\mathrm{HML}_{\mathrm{t}}: \text { Retorno pelo fator de risco razão VC/VM no ano } t ; \\
\mathrm{R}_{\mathrm{H}, \mathrm{t}}: \text { Retorno médio das carteiras } \mathrm{H} \text { no mês } t ; \\
\mathrm{R}_{\mathrm{L}, \mathrm{t}}: \text { Retorno médio das carteiras L no mês } t \text {. }\end{array}$ \\
\hline Prêmio do Payout ${ }_{\mathrm{t}}=\overline{\text { Payout }_{\mathrm{t}}}-\overline{\text { Payout }_{\mathrm{t}}}$ & $\begin{array}{l}\text { Payout } \mathrm{n}_{\mathrm{t}} \text { : média do retorno das ações das companhias que } \\
\text { não pagaram dividendos no mês } t ; \\
\text { Payout } \mathrm{i}_{\mathrm{t}} \text { : média do retorno das ações das companhias que } \\
\text { pagam Payout incremental no mês } t \text {; } \\
\text { Payout } \mathrm{r}_{\mathrm{t}} \text { : média dos retornos das ações das companhias que } \\
\text { pagam Payout reduzido ou mínimo no mês } t \text {. }\end{array}$ \\
\hline
\end{tabular}

Nota. Na primeira coluna está designada a nomenclatura de cada fator e sua equação. Na segunda coluna estão as denominações dos elementos que compõem as equações dos respectivos fatores do modelo.

Fonte: Elaboração própria. 
Após a apresentação dos procedimentos metodológicos operacionais da pesquisa e as definições da população e amostra, bem como a construção do modelo de quatro fatores com Payout, a partir da adaptação do modelo de três fatores de Fama e French, a seção a seguir apresenta e comenta os principais resultados encontrados quanto à avaliação do modelo proposto e a relevância do fator Payout como fator de risco para avaliar o retorno das carteiras formadas.

\section{RESULTADOS}

Para atingir o objetivo de investigar se o modelo adaptado de Fama e French com a inclusão do fator Payout (F\&F com Payout) permitiria melhor compreensão dos retornos das carteiras de companhias listadas na B3 do que o modelo de três fatores de Fama e French, o primeiro passo foi comparar o poder explicativo, a análise de dependência dos resíduos e os testes do ajuste do modelo e da significância dos coeficientes entre os modelos.

Em seguida, os coeficientes e p-valor de cada fator foram analisados a fim de avaliar o efeito que cada um exerce sobre o retorno das carteias. Assim, a Tabela 4 apresenta os resultados do ajuste do modelo; da análise da autocorrelação dos resíduos, a qualidade do ajuste do modelo e a significância dos coeficientes para o modelo original de três fatores de Fama e French (abreviado por F\&F) e o modelo adaptado com a inclusão do fator Payout (abreviado por F\&F com Payout).

Tabela 4

Comparação entre o poder explicativo, a análise de dependência dos resíduos e os testes do ajuste do modelo e da significância dos coeficientes para o modelo de três fatores e o modelo proposto de quatro fatores

\begin{tabular}{|c|c|c|c|c|c|c|c|c|}
\hline \multirow{3}{*}{ Carteira } & \multicolumn{8}{|c|}{ Modelos } \\
\hline & \multirow{2}{*}{$\begin{array}{c}\text { F\&F } \\
R^{2} \text { ajustado }\end{array}$} & \multirow{2}{*}{$\begin{array}{c}\text { F\&F com } \\
\text { Payout } \\
\text { R}^{2} \text { ajustado }\end{array}$} & \multirow{2}{*}{$\begin{array}{c}\text { F\&F } \\
\text { Análise DW }\end{array}$} & \multirow{2}{*}{$\begin{array}{c}\begin{array}{c}\text { F\&F com } \\
\text { Payout }\end{array} \\
\text { Análise DW }\end{array}$} & \multicolumn{2}{|c|}{$\mathbf{F} \& \mathbf{F}$} & \multicolumn{2}{|c|}{ F\&F com Payout } \\
\hline & & & & & Test $\mathrm{F}$ & $\begin{array}{l}\text { Prob. } \\
\text { F }\end{array}$ & Test F & Prob. F \\
\hline SLN & 0,597 & 0,751 & $\begin{array}{c}\text { Sem } \\
\text { autocorrelação }\end{array}$ & $\begin{array}{c}\text { Sem } \\
\text { autocorrelação }\end{array}$ & 96,67 & 0 & 84,61 & 0 \\
\hline SHN & 0,528 & 0,572 & $\begin{array}{c}\text { Sem } \\
\text { autocorrelação }\end{array}$ & $\begin{array}{c}\text { Sem } \\
\text { autocorrelação }\end{array}$ & 57,27 & 0 & 52,47 & 0 \\
\hline SLI & 0,695 & 0,712 & $\begin{array}{c}\text { Sem } \\
\text { autocorrelação }\end{array}$ & $\begin{array}{c}\text { Sem } \\
\text { autocorrelação }\end{array}$ & 114,83 & 0 & 88,11 & 0 \\
\hline SHI & 0,701 & 0,735 & $\begin{array}{c}\text { Sem } \\
\text { autocorrelação }\end{array}$ & $\begin{array}{c}\text { Sem } \\
\text { autocorrelação }\end{array}$ & 125,20 & 0 & 106,69 & 0 \\
\hline SLMR & 0,597 & 0,422 & Inconclusivo & Inconclusivo & 34,91 & 0 & 34,78 & 0 \\
\hline SHMR & 0,687 & 0,437 & $\begin{array}{c}\text { Sem } \\
\text { autocorrelação }\end{array}$ & $\begin{array}{c}\text { Sem } \\
\text { autocorrelação }\end{array}$ & 44,49 & 0 & 33,59 & 0 \\
\hline BLN & 0,498 & 0,526 & $\begin{array}{c}\text { Sem } \\
\text { autocorrelação }\end{array}$ & $\begin{array}{c}\text { Sem } \\
\text { autocorrelação }\end{array}$ & 36,49 & 0 & 42,32 & 0 \\
\hline BHN & 0,574 & 0,671 & $\begin{array}{c}\text { Sem } \\
\text { autocorrelação }\end{array}$ & $\begin{array}{c}\text { Sem } \\
\text { autocorrelação }\end{array}$ & 55,25 & 0 & 51,45 & 0 \\
\hline BLI & 0,420 & 0,531 & $\begin{array}{c}\text { Sem } \\
\text { autocorrelação }\end{array}$ & $\begin{array}{c}\text { Sem } \\
\text { autocorrelação }\end{array}$ & 25,87 & 0 & 19,83 & 0 \\
\hline BHI & 0,339 & 0,437 & $\begin{array}{c}\text { Sem } \\
\text { autocorrelação }\end{array}$ & $\begin{array}{c}\text { Sem } \\
\text { autocorrelação }\end{array}$ & 22,96 & 0 & 18,12 & 0 \\
\hline BLMR & 0,625 & 0,426 & $\begin{array}{c}\text { Sem } \\
\text { autocorrelação }\end{array}$ & $\begin{array}{c}\text { Sem } \\
\text { autocorrelação }\end{array}$ & 19,85 & 0 & 15,01 & 0 \\
\hline BHMR & 0,679 & 0,421 & $\begin{array}{c}\text { Ausência de } \\
\text { autocorrelação }\end{array}$ & $\begin{array}{c}\text { Ausência de } \\
\text { autocorrelação }\end{array}$ & 21,89 & 0 & 16,56 & 0 \\
\hline
\end{tabular}

Nota. $\mathrm{O}$ coeficiente de determinação ( $\mathrm{R}^{2}$ ajustado) indica capacidade de o modelo ser explicado pelas variáveis incluídas no modelo; a análise de Durbin-Watson avalia a autocorrelação dos resíduos. O Test F e a Probabilidade F (Prob. F) são necessários para avaliar o ajuste do modelo e a significância dos coeficientes.

Fonte: Elaboração própria. 
Ao comparar o poder explicativo, o modelo F\&F com Fator Payout permite uma sensível melhoria na explicação do retorno de oito das doze carteiras, possuindo poder explicativo superior ao modelo de $\mathrm{F} \& \mathrm{~F}$ para as carteiras que não pagaram dividendos e que pagaram dividendos incrementais. Configura-se, portanto, como um importante instrumento para a formação e avaliação de carteiras com perfis extremos de distribuição de dividendos, uma vez que obteve um coeficiente $\mathrm{R}^{2}$ ajustado superior a $70 \%$ para essas carteiras.

Quando analisada a superioridade do modelo de quatro fatores com Payout nas carteiras de alto valor, percebe-se que o poder explicativo do modelo variou entre $43 \%$ e $67 \%$. Isso indica um bom ajuste, porém são necessários novos fatores de risco para melhorar ainda mais o poder explicativo do modelo, uma vez que, apesar de indicar uma moderada capacidade explicativa, novas informações podem contribuir para o ajuste do modelo. Nesse caso, é provável que os fatores PIB; momento; inovação; e sustentabilidade, evidenciados por Neves e Leal (2003), Santos, Famá e Mussa (2012), Joode (2011) e Xiao, Faff, Gharghri e Lee (2013), respectivamente, possam contribuir para aprimorar o modelo.

Por sua vez, o modelo de F\&F foi mais robusto para explicar os retornos das carteiras de companhias que pagam dividendos mínimo obrigatório (SLMR; SHMR; BLMR. BHMR), conforme estabelecido em seus estatutos sociais. Destaca-se que os resultados encontrados indicam um poder explicativo superior a $60 \%$, portanto é útil para compreender o retorno de empresas que costumam pagar dividendos.

Dando prosseguimento à análise da construção dos modelos, utilizam-se os testes de Durbin-Watson, o teste $\mathrm{F}$ e a probabilidade $\mathrm{F}$ para avaliar se os modelos foram bem formulados. O teste de Durbin-Watson, em geral, mostrou resultados semelhantes para os dois modelos analisados, uma vez que onze carteiras convergiram, apresentando ausência de autocorrelação. A interpretação de que não existe autocorrelação significa dizer que as observações adjacentes não estão correlacionadas, ou seja, o modelo foi bem ajustado, pois seus resíduos não apresentam correlação (Gujarati, 2006).

$\mathrm{O}$ teste $\mathrm{F}$ e a probabilidade $\mathrm{F}$ indicam a qualidade do ajuste do modelo e a significância dos coeficientes. O resultado do Test $\mathrm{F}$, quando maior que dez, indica que o modelo é bem ajustado. Portanto o modelo foi bem ajustado para todas as doze carteiras dos dois modelos. A probabilidade $\mathrm{F}$ indica que podemos rejeitar a $1 \%$ de significância que todos os coeficientes são simultaneamente iguais a zero, ou seja, pelo menos um parâmetro é diferente de zero para os dois modelos.

Ante o exposto, é possível afirmar que o modelo F\&F com Payout foi mais eficiente em explicar o retorno das carteiras pequenas e grandes que não pagam dividendos ou que pagam dividendos incrementais. Ao passo que o modelo de três fatores se aplica melhor para as carteiras que pagam dividendos mínimo ou reduzidos. Assim, o modelo de quatro fatores pode ser utilizado para as decisões de investimentos quando se deseja considerar as informações de anormais de distribuição de dividendos.

Dando continuidade à análise comparativa dos modelos, o próximo passo foi realizar a análise de regressão para os dois modelos, a fim de identificar os efeitos dos fatores de risco sobre o retorno das carteiras. Após a análise da distribuição de normalidade dos dados por meio do teste de Kolmogorov-Smirnov e Lilliefors, que confirmou a hipótese de normalidade, prosseguiu-se com as regressões para cada uma das doze carteiras.

A Tabela 5 apresenta o resultado das regressões para o modelo de três fatores de F\&F e modelo de quatro fatores proposto neste estudo (F\&F com Payout), indicando a relevância dos fatores de risco e o coeficiente do modelo para cada carteira. Na Tabela 5, os valores destacados em negrito correspondem aos coeficientes dos fatores de risco que apresentaram significância estatísticas a 5\%, uma vez que seus resultados para $p$-value ficaram abaixo de 0,005. Convém destacar que, quanto menor os resultados do $p$-value, mais significativos estatisticamente são seus coeficientes. Na última coluna, apresenta-se o coeficiente de determinação da regressão para cada carteira, indicando que, quanto mais próximo de um, melhor é o ajuste do modelo. 
Nesse sentido, deve-se observar quais fatores são relevantes e se o modelo foi bem definido para cada perfil de carteira formulada.

Conforme apresentado na Tabela 5, é possível verificar que, para o modelo de Fama e French (1993), os coeficientes do prêmio pelo fator risco de mercado foram significantes em todas as doze carteiras. Ao analisar os coeficientes do fator SMB, foi possível identificar que em apenas uma carteira não houve significância estatística, o caso em questão ocorreu na carteira SHMR Verificou-se também que os valores dos coeficientes se mantiveram positivos para as carteiras Small e negativos para as carteiras Big, o que indica que empresas menores apresentam maiores retornos, corroborando com Fama e French (1993).

Ainda em relação ao modelo de três fatores, analisando o fator HML, seus coeficientes apresentaram significância em metade das carteiras analisadas e com efeito positivo e negativo. Dentre os coeficientes significativos, esse fator apresentou o maior impacto nas carteiras pequenas e que não pagaram dividendos, SLN e SHN com coeficientes de $-1,507$ e 1.705, respectivamente. De forma geral, pode-se dizer que as empresas com maiores oportunidades de crescimento (High) têm relação positiva com o retorno, e aquelas com menores oportunidades de crescimento (Low) apresentam, em sua maioria, relação negativa com o retorno.

No que concerne à discussão dos coeficientes do modelo de quatro fatores, ao examinar os coeficientes do fator prêmio pelo fator risco de mercado, nota-se que foi significante em todas as doze carteiras, tal como no modelo de três fatores, este mesmo comportamento foi observado para o fator SMB, que se manteve estatisticamente significativo para todas as carteiras, exceto para a SHMR. Essa conclusão também foi obtida no modelo de F\&F. Uma possível razão para isso é o fato de que o teste de Durbin-Watson foi inconclusivo para essa carteira.

Ainda em relação ao fator SMB, verificou-se que os valores dos coeficientes se mantiveram positivos para as carteiras Small e negativos para as carteiras Big, indicando existir relação positiva entre o retorno das carteiras e as carteiras de menor valor e uma relação inversa entre o retorno das carteiras e as carteiras de maior tamanho. Convém lembrar que o fator SMB foi mensurado pela proxy valor de mercado das companhias e destaca-se que esse resultado converge com os resultados de Fama e French (1993) ao indicarem que o investidor exige um retorno maior de ações de menor valor de mercado do que as ações de alto valor de mercado.

No tocante à análise do fator Payout, verifica-se que em nove das doze carteiras os coeficientes foram significativos, apresentando impacto negativo para as quatro carteiras cujas companhias não pagaram dividendos (SLN, SHN, BLN, BHN), implicando dizer que, quanto maior o retorno dessas carteiras, menor é a probabilidade de existir um prêmio pelo fator Payout. Ou seja, não pagar dividendos afeta positivamente o retorno das carteiras.

Quanto ao impacto significativo e positivo desse fator nas carteiras estudas, verificou-se que, nas carteiras SLI, SHI, SLMR, BLI e BHI, o pagamento de Payout incremental e do mínimo reduzido implicam em maior retorno das carteiras. Isso indica que as carteiras formadas por empresas de pequeno e grande valor e que pagam dividendos incrementais estão mais propensas a retornos maiores na medida em que pagam mais dividendos. Essa lógica corrobora com as discussões da teoria da relevância dos dividendos (Lintner, 1956; Gordon, 1959), uma vez que pagar dividendos constantes e maiores representa ganhos certos no presente e que a valorização da ação é um evento incerto no futuro. Posto isso, pagar dividendos corrobora para reduzir a incerteza, o que, por sua vez, implica no aumento dos preços das ações da companhia. 
Tabela 5

Resultados das regressões de séries temporais para o modelo de F\&F e o modelo F\&F com Payout

\begin{tabular}{|c|c|c|c|c|c|c|c|c|c|c|c|c|}
\hline \multirow[b]{2}{*}{ Carteira } & \multicolumn{2}{|c|}{ Constante } & \multicolumn{2}{|c|}{ Rm-Rf } & \multicolumn{2}{|c|}{ SMB } & \multicolumn{2}{|c|}{ HML } & \multicolumn{2}{|c|}{ Payout } & \multicolumn{2}{|c|}{$\mathbf{R}^{2}$ ajustado } \\
\hline & $\mathrm{F} \& \mathrm{~F}$ & $\begin{array}{c}F \& F \text { com } \\
\text { Payout }\end{array}$ & $\mathrm{F} \& \mathrm{~F}$ & $\begin{array}{c}F \& F \text { com } \\
\text { Payout }\end{array}$ & $\mathrm{F} \& \mathrm{~F}$ & $\begin{array}{c}F \& F \text { com } \\
\text { Payout }\end{array}$ & $\mathrm{F} \& \mathrm{~F}$ & $\begin{array}{c}F \& F \text { com } \\
\text { Payout }\end{array}$ & $\mathrm{F} \& \mathrm{~F}$ & $\begin{array}{c}F \& F \text { com } \\
\text { Payout }\end{array}$ & $\mathrm{F} \& \mathrm{~F}$ & $\begin{array}{c}F \& F \text { com } \\
\text { Payout }\end{array}$ \\
\hline SLN & 0,125 & $-0,187$ & 0,420 & 0,371 & 1.226 & 0,792 & $-\mathbf{1 , 5 0 7}$ & -1.906 & \multirow{12}{*}{$\begin{array}{l}\text { Não se } \\
\text { aplica }\end{array}$} & $-0,650$ & 0,597 & 0,751 \\
\hline SHN & 1.231 & 1.453 & $\mathbf{0 , 5 8 9}$ & 0,601 & 1,352 & 0,781 & 1.705 & 1.952 & & $-0,576$ & 0,528 & 0,572 \\
\hline SLI & 0,642 & 0,721 & 0.941 & 0,953 & $\mathbf{0 , 3 1 2}$ & 0,275 & 0.109 & 0,096 & & 0,175 & 0,695 & 0,712 \\
\hline SHI & 0,254 & 0,367 & $\mathbf{0 , 8 7 6}$ & 0,861 & 0,261 & 0,452 & 0,179 & 0,101 & & 0,356 & 0,701 & 0,735 \\
\hline SLMR & 1.992 & 1.671 & 0,954 & 0,206 & 0,405 & 0,193 & $-0,751$ & $-\mathbf{0 , 8 3 6}$ & & $\mathbf{0 , 5 5 9}$ & 0,597 & 0,422 \\
\hline SHMR & $-0,156$ & $-0,161$ & 0,705 & $\mathbf{0 , 0 9 7}$ & 0,205 & 0,103 & 0,251 & 0,276 & & $-0,108$ & 0,687 & 0,437 \\
\hline BLN & 3.421 & 3.157 & $\mathbf{0 , 9 8 1}$ & 0,941 & $-\mathbf{0 , 3 5 7}$ & $-0,976$ & $-0,621$ & $-0,401$ & & $-0,901$ & 0,498 & 0,526 \\
\hline BHN & 0,789 & 0,624 & 0,905 & $\mathbf{0 , 8 1 3}$ & $-\mathbf{0 , 1 8 1}$ & $-\mathbf{0 , 5 2 9}$ & 0,159 & 0,281 & & $-0,291$ & 0,574 & 0,671 \\
\hline BLI & -1.742 & -1.621 & 0,669 & 0,471 & $-\mathbf{0 , 3 8 2}$ & $-0,326$ & $-0,091$ & $-0,054$ & & $\mathbf{0 , 1 7 1}$ & 0,420 & 0,531 \\
\hline BHI & 1,109 & 1,223 & 0,491 & $\mathbf{0 , 3 8 9}$ & $-0,479$ & $-0,421$ & $-0,059$ & $-0,088$ & & 0,221 & 0,339 & 0,437 \\
\hline BLMR & 0,351 & 0,412 & 0,689 & 0,621 & $-\mathbf{0 , 5 8 9}$ & $-\mathbf{0 , 5 2 3}$ & $-0,179$ & $-0,201$ & & 0,197 & 0,625 & 0,426 \\
\hline BHMR & 1.792 & 1.297 & $\mathbf{0 , 8 1 5}$ & $\mathbf{0 , 8 1 2}$ & $-0,402$ & $-0,325$ & 0,089 & 0,023 & & 0,059 & 0,679 & 0,421 \\
\hline
\end{tabular}

Nota. A variável dependente do modelo, denominada de prêmio de mercado da carteira, considera o retorno anual da carteira em relação ao ativo livre de risco. Para a formação

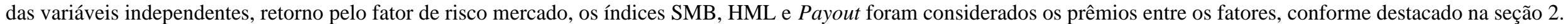
Nesta tabela são apresentados os coeficientes das variáveis, os respectivos valores de significância e o $\mathrm{R}^{2}$ ajustado para cada regressão.

Fonte: Dados da pesquisa.

Também pode ser visto que as empresas não pagadoras de dividendos possuem relação negativa com o retorno, indicando que os acionistas valorizam o pagamento de dividendos e, quando as empresas não o fazem, há um impacto negativo no retorno dado à desvalorização das carteiras. Ante o exposto, pode-se dizer que os resultados desta pesquisa culminam com a teoria do pássaro na mão (Gordon, 1963; Lintner, 1962), posto que os acionistas preferem o pagamento de dividendos correntes a dividendos futuros ou ganho de capital. 
Quando analisado os fatores em conjunto, foi possível observar que apenas as carteiras SLMR e BLN, dentre as doze carteiras, apresentaram significância em todos os fatores simultaneamente, e as carteiras SLN, SHN, BHN, BLI apresentaram significância em quatro fatores, incluindo a constante, confirmando que, em geral, os fatores do modelo proposto neste estudo são relevantes e têm relação com os retornos das carteiras elaboradas. O fator Payout foi relevante em nove das doze carteiras.

Isso posto, pode-se dizer que a qualidade do modelo F\&F com Payout, informação obtida pelo $\mathrm{R}^{2} \mathrm{a}$, que indica o quanto o modelo proposto é capaz de explicar o retorno das carteiras a partir das variáveis estudadas, é adequado para explicar os retornos das carteiras SLN, SLI, SHI, BHI com mais de $60 \%$ e, para as demais, tem poder explicativo entre $40 \%$ e $50 \%$.

Vale ainda destacar que a relação positiva das empresas pagadoras de dividendos com o retorno está de acordo com os achados de Gordon (1959), pautado na explicação de que altos pagamentos de dividendos reduzem o custo de capital de terceiros e, consequentemente, aumentam o valor das ações. Além disto, Gordon (1959) comenta que os investidores são avessos ao risco e ao se encontrarem em um ambiente de incerteza, optarão por receberem os dividendos o quanto antes.

De acordo com os resultados obtidos nesta pesquisa, pode-se dizer que o modelo F\&F com Payout F\&F com Payout é relevante teórico e empiricamente nas diversas decisões financeiras, sobretudo no que tange ao processo de formação de carteiras e decisão de investimentos, uma vez que ao considerar o prêmio pelo pagamento de dividendos, o modelo se mostrou relevante para explicar o retorno das carteiras de ações, corroborando com a teoria da relevância dos dividendos, a qual sugere que o pagamento de dividendos contribui para adicionar valor às ações, conforme Lintner, (1962), Gordon (1963) e mais recentemente com os resultados de Loss e Sarlo Neto (2006), Mussa, Rogers e Securato (2009), Martins e Fama (2012) e de Melo e Fonseca (2015)

\section{CONCLUSÕES}

Esta pesquisa teve como objetivo investigar se o modelo adaptado de Fama e French com a inclusão do fator Payout (F\&F com Payout) permitiria melhor compreensão dos retornos das carteiras de companhias listadas na B3 do que o modelo de três fatores de Fama e French.

A inclusão do fator Payout ao modelo de avaliação de ativos se justifica a partir da ausência de consenso da relação entre o valor pago dos dividendos e o valor da ação, configurando-se, portanto, uma oportunidade de realizar uma adaptação ao modelo de fama e French e testar sua eficiência em explicar o retorno das carteiras formadas por empresas negociadas na Brasil, Bolsa, Balcão entre 2014 e 2018 e, consequentemente, contribuir no processo de formação de carteiras e decisão de investimentos.

Em resposta ao objetivo desta pesquisa, de evidenciar o poder explicativo do modelo e, por conseguinte, a questão-problema que guia este estudo - qual o impacto da adição do fator Payout ao modelo Fama e French nas explicações das variações dos retornos das ações para as companhias de capital aberto do Brasil -, descobriu-se que a adaptação do modelo de Fama e French (1993) foi bem estimada e capaz de explicar o retorno das carteiras a partir das variáveis estudadas e, em sua maioria, com poder explicativo maior que o modelo de três fatores.

Nesse sentido, o modelo de quatro fatores com Payout é melhor do que o modelo de três fatores em explicar o retorno de oito das doze carteiras, sendo que, para as carteiras de menor valor (small) que não pagaram dividendos e que pagaram dividendos incrementais SHI, SLI, SLN, SHN, o modelo consegue explicar o retorno em 70\%. E, nas carteiras de alto valor, o poder explicativo variou entre $43 \%$ e $67 \%$. Portanto a inclusão do fator Payout ao modelo de Fama e French (1993) é relevante para os estudos de avaliação de portfólios.

Ante o exposto pode-se inferir que esta pesquisa é útil aos investidores, uma vez que evidencia o pagamento dos dividendos como fator relevante para a formação de carteiras e que o 
fator Payout tem importância quando adicionado ao modelo de três fatores de Fama e French, configurando-se como uma alternativa para auxiliar na formação de carteiras e decisão de investimento, principalmente ao considerar a política de distribuição de dividendos.

Convém destacar que esta pesquisa corrobora a teoria da relevância dos dividendos (Lintner, 1956; Gordon, 1959) e do pássaro na mão (Lintner, 1962; Gordon, 1963), uma vez que encontrou relação positiva entre pagamento de dividendos e o retorno das carteiras, permitindo inferir que existe associação positiva entre eles e, portanto, que o pagamento de dividendos contribui para a valorização das carteiras de empresas que pagam dividendos normais e incrementais.

Por fim, como sugestão para pesquisas futuras, recomenda-se identificar as causas para o fator Payout exercer um impacto negativo nas carteiras SLN, SHN, BLN e BHN, bem como a realização de pesquisas a fim de investigar qual a informação que as empresas desejam transmitir ao distribuírem dividendos incrementais.

\section{REFERÊNCIAS}

Almeida, L. A. G., Pereira, E. T., \& Tavares, F. O. (2015). Determinantes da política de dividendos: evidência de Portugal. Revista Brasileira de Gestão de Negócios, 17(54), 701719 .

Azevedo, V. G. (2014). Análise do impacto da inclusão do Fator Sustentabilidade Empresarial no Modelo de Três Fatores De Fama E French nas empresas negociadas na BM\&FBOVESPA - um estudo empírico entre o período de 2006 e 2013. Dissertação de Mestrado, Programa de Pós-Graduação em Engenharia da Produção, Universidade Federal de Santa Catarina, Florianópolis.

Baker, H. K., \& Powell, G. E. (1999). How corporate managers view dividend policy. Quarterly Journal of Business and Economics, 17-35.

Baker, H. K., Farrelly, G. E., \& Edelman, R. B. (1985). Survey of Management Views on Dividend Policy. Financial Management, 14(14), 78-84.

Carhart, M. M. (1997). On Persistence in Mutual Fund Performance. The Journal of Finance, 52(1), 57-81.

De Melo, F. J, \& Da Fonseca, M. W. (2015). Política de dividendos no Brasil: uma análise na reação do mercado a anúncios de distribuição de proventos. Revista Contemporânea de Contabilidade, 12(27), 137-164.

Decourt, R. F., \& Procianoy, J. L. (2012). O Processo Decisório sobre a Distribuição de Lucros das Empresas Listadas na BM\&FBOVESPA: Survey com CFOs. Revista Brasileira de Finanças, 10(4), 461-498.

Fama, E. F., \& French, K. R. (1992). The cross-section of expected stock returns. The Journal of Finance, 47(2), 427-465.

Galvão, K. S, Santos, J. F., \& Araújo, J. M. (2018). Dividendos, juros sobre capital próprio e níveis de payout: Um estudo investigativo sobre a política de distribuição de dividendos adotada pelas empresas listadas na BM\&FBovespa. Revista Contemporânea de Contabilidade, 15(36), 3-30. 
Gordon, M. (1959). Dividends, earnings and stock prices. The Review of Economics and Statistics, 41(2), 99-105.

Gordon, M. (1963). Optimal Investment and Financing Policy. The Journal of Finance, 28(2)264-272.

GUJARATI, D. N. Econometria básica. 4a. Rio de Janeiro: Elsevier, 2006

Joode, N. V. W. (2011). The relationship between innovation and stock returns Does innovation explain stock market returns? 2011. 54 f. Dissertação de Mestrado, Departamento de Finanças da Faculdade de Economia e Administração, Tilburg University, Holanda.

Lagioia, U. C. T., Maciel, C. V., \& Libonati, J. J. (2008). Aspectos pagamento de juros sobre o capital próprio $\mathrm{x}$ distribuição de dividendos pela óptica tributária. Anais do Congresso Brasileiro de Contabilidade, Gramado, RS, Brasil, 18.

Leite, M, Bogoni, N. M., \& Hein, N. (2019). Revisitando os determinantes da distribuição de dividendos: uma análise em empresas brasileiras. Revista Ambiente Contábil, 11(1) 58-76.

Lintner, J. (1956). Distribution of incomes of corporations among dividends, retained earnings and taxes. American Economic Review, 46(2), 97-113.

Lintner, J. (1962). Dividends, earnings, leverage, stock prices and the supply of capital to corporations. The Review Economics and Statistics, 44(3), 243-269.

Loss, L., \& Sarlo Neto, A. (2006). O inter-relacionamento entre políticas de dividendos e de investimentos: estudo aplicado às companhias brasileiras negociadas na Bovespa. Revista Contabilidade \& Finanças, 17(40), 52-66.

Malaga, F. K., \& Securato, J. R. (2004). Aplicação do modelo de três fatores de Fama e French no mercado acionário brasileiro: um estudo empírico no período 1995-2003. Anais do Encontro Nacional da Associação Nacional de Pós-Graduação e Pesquisa em Administração, Curitiba, PR, Brasil, 28 de setembro de 2004.

Martins, A. I., \& Fama, Rubens. (2012). What the studies conducted in Brazil regarding dividend policy reveal? RAE, 52(1), 24-40.

Miller, M., \& Modigliani, F. (1961). Dividend policy, growth, and the valuation of share. Journal of Business, 40(4) 411-433.

Mussa, A., Rogers, P., \& Securato, J. R. (2009). Modelos de retornos esperados no mercado brasileiro: testes empíricos utilizando metodologia preditiva. Revista de Ciências da Administração, 11(23), 192-216.

Neves, M. B. E., \& Leal, R. P. C. (2003). Anomalias no Mercado de Ações e o Crescimento do PIB Brasileiro. Cadernos Discentes COPPEAD, 54(18), 5-31.

Ross, S. (1976). An Arbitrage Theory of Capital Asset Pricing. Journal of Economic Theory, 13(3), 341-360. 
Santana, L. (2006). Relação entre Dividend Yield e retorno das ações abordando aspectos determinantes da política de dividendos: um estudo empírico em empresas ações negociadas na BOVESPA. Dissertação de Mestrado, Programa de Pós-Graduação em Ciências Contábeis, Fundação Instituto Capixaba de Pesquisa em Contabilidade, Economia e Finanças (FUCAPE), Vitória.

Santos, J. O., Famá, R., \& Mussa, A. (2012). A adição do fator de risco momento ao modelo de precificação de ativos dos três fatores de Fama \& French aplicado ao mercado acionário brasileiro. Revista de Gestão REGE, 19(3), 453-472.

Veiga, A. Z., Imbrosio, D. A., \& Ferreira, L. F. (2008). Remuneração aos acionistas e os reflexos tributários no resultado da empresa: um estudo de caso em uma instituição financeira. Revista Catarinense da Ciência Contábil, 7(19), 17-32.

Vieira, M. D. V., Maia, V. M., Klotzle, M. C., \& Figueiredo, A. C. (2017). Modelo de Cinco Fatores de Risco: Precificando Carteiras Setoriais no Mercado Acionário Brasileiro. Revista Catarinense da Ciência Contábil, 16(48), 86-104.

Xiao, Y., Faff, R., Gharghori, P., \& Lee, D. (2013). An empirical study of the world price of sustainability. Journal of Business Ethics, 114(2), 297-310. 